\title{
Auto-estima e relações afetivas ${ }^{1}$
}

\author{
Antônio Isidro da Silva ${ }^{2}$ \\ Geison Isidro Marinho ${ }^{3}$
}

\begin{abstract}
RESUMO - Sentimentos são resultantes de acontecimentos ambientais; não tem geração espontânea. As sensações agradáveis ou ruins, descritas como sentimentos, são respostas discriminativas das ações do ambiente sobre o organismo ou as conseqüências - reforçadoras ou aversivas - de algum comportamento. A autoestima é desenvolvida com os elementos fornecidos de relações familiares e sociais. Esses elementos, entretanto, nem sempre fornecem informações positivas a respeito de si próprio e, à medida que o indivíduo cresce precisa-se identificar quem verdadeiramente ele é e assumir a responsabilidade pela própria existência.
\end{abstract}

Palavras-chave: Terapia comportamental, auto-estima e relações afetivas.

\section{Self-esteem and feeling relationships}

\begin{abstract}
Feelings are results of environmental happenings; they do not have spontaneous generation. The pleasurable or uncomfortable sensations, described as feelings, are discriminative responses of the actions of the environment upon the organism or the consequences - positive or aversive - of some behavior. The selfesteem is developed with the elements provided by familiar and social relations. These elements, however, rarely provide positive informations about the individual itself and, as the individual grown up it is needed to identify who he really is and assume the responsibility for his own existence.
\end{abstract}

Key words: Behavior therapy, self-esteem and feeling relationships

1 Artigo baseado em Tema Livre apresentado na I Semana de Psicologia e Terapia Comportamental do UniCEUB, de 22 a 25/04/1998 e em palestra apresentada no ICiclo de Palestras do INSPAC - Instituto São Paulo de Terapiae Análise do Comportamento, em 08/06/2002.

2 Especialista em Psicologia Experimental e Psicologia Clínica. Psicólogo Clínico AnalíticoComportamental, Professor dePsicologia doUniCEUB, Professor do Curso de Formaçãoe Treinamentoem Psicoterapia Analítico-Comportamental do INSPAC.

3 Mestre em Psicologia pela UnB. Psicólogo Clínico Analítico-Comportamental, Professor de Psicologia do UniCEUB, Professor do Curso de Formaçãoe Treinamento em Psicoterapia Analítico-Comportamental do INSPAC. 
O termo auto-estima é bastante conhecido e utilizado na linguagem cotidiana e na Psicologia. Segundo Ferreira (2000) "auto" quer dizer por si mesmo e "estima"; sentimento de valor atribuído a alguém ou valor dado a alguma coisa, apreço, consideração. A expressão "auto-estima" não se encontra definida nesse dicionário (Aurélio) de uso popular.

Essa definição levanta algumas questões para o terapeuta analíticocomportamental que, em seu consultório, freqüentemente escuta pessoas se queixarem de sua baixa auto-estima, carência ou falta de valor. Como o indivíduo desenvolve sua noção de valor? E, como ele vai se sentir competente, com direitos nesse mundo?

\section{O sentir sobre si mesmo}

Segundo Skinner (1991) "a cultura louva e recompensa os seus membros que fazem coisas úteis ou interessantes. No processo, o comportamento é positivamente reforçado e são geradas condições corporais que são observadas pela pessoa cujo eu é observado e valorizado" (p.47). Essas condições corporais - meio interno - se alteram em função de mudanças que ocorrem no ambiente. Nesse caso, é explorando as circunstâncias ambientais geradoras desses sentimentos que se identifica o que faz a pessoa sentir o que sente e como ela passou a se sentir daquela forma.

Do mesmo modo que reforçadores positivos geram sensações agradáveis, as críticas e punições podem gerar condições corporais adversas. A pessoa que é valorizada, reconhecida sente-se competente e aquela que é punida e criticada diante de seus feitos sente-se incompetente. Assim, à medida que há a interação com o ambiente, a referência individual de si mesmo é construída. Essa referência pode ser positiva ou negativa.

\section{Organização do repertório}

Do ponto de vista comportamental, o indivíduo, ao nascer, é essencialmente incompetente e carente de cuidados. Os pais são os responsáveis diretos por esse novo ser. São eles que vão fornecer os cuidados iniciais para a sobrevivência do indivíduo e as primeiras oportunidades de relacionamento social. Se os pais acolhem o filho, protegem-no, alimentam-no e corrigem seus comportamentos indesejáveis, vão fazer com que esse filho se observe positivamente, se sinta aceito e perceba que tem importância para os outros. Mas se os pais não agirem dessa forma, o filho poderá se sentir inadequado, desprotegido e carente.

O bebê não possui uma noção de "EU". Entretanto, os pais, os irmãos e 
outras pessoas com quem interage, ensinam o indivíduo a descrever seu próprio corpo ("olha a mãozinha dele"; "que bonitinho o narizinho dele") e seu próprio comportamento ("neném fez xixi?"). As ações dos outros também são descritas pelos pais ("olha que lindo o que sua irmã fez") e esse conjunto de descrições tornar-se-á referência para a construção da noção de "EU" na medida em que o bebê se desenvolve.

Segundo Baldwin e Baldwin (1986), a criança aprende a fazer auto-descrições quando realiza algo ("olha o que eu fiz"). Se esse comportamento for aprovado socialmente, sua ação e a auto-descrição serão reforçados. Por outro lado, se houver punição para o comportamento, é bastante provável que o agir e o descrever a ação reduzam de freqüência. Diante dessas contingências, a criança passa a perceberse mal, pois juntamente com a dica pública ocorrem alterações emocionais relacionadas ao que foi dito sobre ela.

$\mathrm{O}$ ambiente hostil leva as pessoas a se sentirem insignificantes, sem valor e elas podem se sentir culpadas porque se sentem incapazes de promover ou adquirir o reforço desejado (e.g. o afeto do outro). As contingências, em termos de ambiente hostil, não servem apenas para inibir comportamentos, mas promovem o desenvolvimento de eventos privados, a partir dos quais o indivíduo se responsabiliza pelo seu próprio fracasso e não discrimina como o ambiente pode leva-lo a sentir-se como se sente.

Baldwin e Baldwin (1986) afirmam que, quem é freqüentemente punido, aprende a responder a um grande número de estímulos condicionados (CS's) para respostas emocionais aversivas, tais como vergonha, ansiedade, culpa ou sentimentos ruins a respeito de si próprio. Por outro lado, o comportamento vai ser mais assertivo se a maioria das auto-descrições da pessoa se constitui de CS's para emoções agradáveis devido a uma história de experiências positivas.

$\mathrm{O}$ auto-conhecimento sobre atitudes e crenças internas freqüentemente depende de discriminações que envolvem muitos eventos ao longo do tempo, mas os eventos são mais públicos do que privados. (Baum, 1999, p. 122). Segundo Ryle (1949) e Rachlin (1985) (citados em Baum, 1999, p.121), tendemos a acreditar mais no que as pessoas dizem. Então, ao ser muito criticada, censurada ou rejeitada, uma pessoa passa a acreditar e a se ver de maneira inadequada. A ausência de auto-conhecimento pode dar pistas sobre alguém que acredita nas críticas que os outros lhe fazem por certos comportamentos, roupas que vestem e etc. Além de pistas sobre alguém que não observa classes outras de respostas que foram positivamente reforçadas no passado. Nesse sentido, há a supressão da resposta punida além de outras respostas semelhantes. Isso produz um indivíduo inibido, que tem medo de falar em público e colocar-se de maneira assertiva. O controle aversivo favorece o aparecimento de respostas emocionais negativas e um repertório 
de fuga e esquiva.

O controle público é bem observado nesses comportamentos de fuga e esquiva, onde os arranjos de contingências que levaram à auto-observação negativa também mantém e fortalecem esses comportamentos. O indivíduo, portanto, prevendo sofrimento ou fracasso evita determinados contextos. Se ele sente-se feio, desajeitado e acredita que a pessoa amada não vai querê-lo, "prefere" sentirse mal a enfrentar uma situação de conquista. Com medo de ser rejeitado, o indivíduo não se expõe e mantém o sentir-se inferior e sem direitos. Diante desse contexto, a seguinte regra é desenvolvida "não sou bom o suficiente para conseguir alguém".

Comparações feitas pelos outros também alteram os comportamentos (públicos e privados) de um indivíduo. As comparações estabelecem um referencial para comportamentos apropriados e desejáveis. Ou seja, um pai que compara o filho ao primo estudioso está "dizendo" ao filho que comportamento deveria ter. O filho, por sua vez, achando que não agrada ao pai, tenta se comportar como o primo. Se conseguir bons resultados e o pai o valorizar, o filho se sentirá melhor.

No ambiente social são feitas observações sobre comportamentos ditos adequados e pertences de valor. A partir de dessas observações, o indivíduo pode também começar a se comparar para identificar o que os outros têm, que é valorizado, e ele não. A constatação das diferenças sinaliza o que é admirado e valorizado socialmente. Percebendo-se falho, o indivíduo avalia-se inferior e supervaloriza o outro. E então, para receber reforço, passa a se comportar de maneira a obter reconhecimento; passa a usar determinadas roupas, comprar carros, valorizar determinados comportamentos (e.g. falar sobre moda, carros) e fazer o que as pessoas que ele admira fazem para ser aprovado socialmente ou pela família (e.g. estudar muito). Porém, mesmo mudando seus comportamentos e obtendo as coisas das quais ache que precisa, o indivíduo sente-se sozinho e incapaz de obter o afeto do outro.

Ao discriminar que pode não ser valorizado pelo outro, o indivíduo pode emitir comportamentos agressivos. Para a pessoa, é uma forma de defender-se da humilhação (do não querer do outro), porém, a partir daí, uma cadeia de comportamentos inassertivos pode ser observada: o indivíduo sente-se inferior, o outro faz algum comentário sobre alguma idéia, o indivíduo agride como se estivesse defendendo a auto-estima e o outro se afasta. Nesse sentido, são confirmadas a sensação de inferioridade e a regra de que "os outros não gostam de mim". A outra pessoa se afastou em função da agressão e o indivíduo fica pensando que é porque é rejeitado. A outra pessoa apenas contra argumentou uma idéia, mas o indivíduo se sentiu ofendido. Pergunta-se: O outro ofendeu ou ele se sentiu ofendido? 
Quando as pessoas estão expostas a contingências que não conseguem discriminar, tendem a formular e seguir auto-instruções. Então, assumem comportamentos defensivos para se esquivarem da suposta fragilidade que o precisar do outro impõe (e.g. "não devo demonstrar o que sinto senão as pessoas vão se aproveitar de mim, vão achar que sou fácil"). Dessa forma, não percebendo com clareza o mundo a sua volta, esses indivíduos pensam que todos estão contra eles e que não são aceitos. Na verdade, essas pessoas não discriminam o contexto e não percebem como suas ações podem afastar os outros, as quais tanto desejam.

\section{Relacionamento interpessoal}

Se a pessoa não tem um repertório de habilidades mais adequadas para lidar com sucesso em relacionamentos interpessoais, o comportamento agressivo pode ser um dos meios. No passado, os pais, por exemplo, usaram da punição ("como é que você faz isso, é idiota"?) na tentativa de suprimir comportamentos indesejáveis, e estabelecem uma relação de funcionalidade entre o comportamento agressivo e aquele contexto (os pais tinham sucesso na supressão do comportamento aprendizagem). Qualquer situação futura de desacordo ou conflito fornece dicas para a emissão de comportamentos agressivos. Historicamente, esse comportamento pode ter funcionado com "coleguinhas", na escola e no ambiente infantil, porém, em relações interpessoais na vida adulta, a agressividade pode não ter efeitos satisfatórios, havendo grande probabilidade do indivíduo agressivo ser isolado.

Quando o cliente chega ao consultório as queixas relacionadas a auto-estima giram em torno de temas como: não ser amado por ninguém, sentimentos de inadequação, não conseguir se relacionar ou manter relacionamentos, solidão e sentimentos de injustiça. Nas relações interpessoais pessoas com baixa auto-estima emitem comportamentos que dificultam seu relacionamento com os demais. Quando vivem relações afetivas mais intimas, essas pessoas se queixam da vida e fazem cobranças de afeto, consideração e respeito, como se as pessoas a sua volta não a valorizassem. Esse padrão de comportamento incomoda quem está por perto, o que, em geral, é relatado como "estou me sentindo sugado por fulano de tal. Nunca consigo fazer o suficiente para agrada-lo".

A auto-estima não deve ser considerada causa de comportamento. O sentir deve ser considerado ocasião para a emissão de comportamentos, em que, segundo Skinner (1991) "um organismo raramente se comporta sem responder a seu próprio corpo" (p. 46). Por outro lado, deve-se dar especial atenção ao tratamento da autoestima na clínica psicológica, pois a forma como a pessoa se observa (adequada ou inadequada) e observa os outros, especifica o modo como ela se relaciona com os outros: com direitos ou não, relaxada ou tensa, com ou sem comportamentos 
assertivos ou habilidades sociais.

É importante lembrar que nas interações com o meio, uma pessoa também é "ambiente" para as outras, pois estímulos produzidos por ela vão afetar os outros indivíduos. Os comportamentos operantes modificam o ambiente e essas modificações levam, por sua vez, a modificações em comportamentos subseqüentes, tanto do próprio emissor quanto de quem está a sua volta.

As pessoas com baixa auto-estima são muito carentes de afeto. Essa carência geralmente é histórica, quando os pais não a atenderam afetivamente e foi gerada uma sensação de desproteção. Para obter "proteção" (segurança afetiva) vai-se fazer necessária a presença do outro (reforço) na vida delas e, precisar do outro muitas vezes as coloca numa condição de fragilidade. A fragilidade é observada, pois o outro pode não estar disponível quando elas solicitam, o que pode provocar sentimento de humilhação. Como consequiência última, portanto, essas pessoas esquivam-se do relacionamento interpessoal e não demonstram ao outro a sua importância.

Ao sentir-se inferior, o indivíduo pode pensar que não têm nada que agrade aos outros e se coloca nos relacionamentos sem direitos (e.g. "fulano é tão legal... mas eu não tenho a menor chance com ele. Ele não vai querer alguém burra como eu"). A ausência de um repertório adequado faz com que pessoas com baixa autoestima se comportem com timidez e retraimento e muitas vezes vistas como "metidas" (e.g. "fulana passou por mim hoje e nem me olhou, como é metida a besta!"), sendo que, na realidade, essas pessoas não possuem um repertório de habilidades sociais apropriado para se relacionarem.

\section{Tratamento}

Atribuir à baixa auto-estima a causa dos fracassos é atribuir um valor causal à auto-estima e isso implica em negligenciar a história de aprendizagem. Essa prática não fornece condições de o psicólogo clínico realizar alguma mudança no sentir das pessoas, pois se ignoram as contingências que a mantém esse sentimento. O sentimento é algo interno que muda apenas se a pessoa se dispuser a sentir e a agir de uma forma diferente.

Conforme Skinner (1953) "a prática de buscar dentro do organismo uma explicação para o comportamento tende a obscurecer as variáveis que estão disponíveis de forma imediata para uma análise científica. Estas variáveis se encontram fora do organismo, em seu ambiente e em sua história ambiental" (p.41). Durante muito tempo acreditou-se que o comportamento se originava dentro do indivíduo - talvez porque vemos o comportamento humano, mas percebemos muito pouco do processo através do qual ele se origina, sentimos necessidade de 
um eu criativo, iniciador (Skinner, 1991).

Para fazer análise de um sentimento, deve-se levar em consideração os antecedentes e conseqüentes desse comportamento de sentir. Para o terapeuta, o que se sente é tão importante quanto o que se faz. Relatos do mundo interno - do que é sentido e introspectivamente observado - dão dicas (1) do comportamento passado e das condições que o afetaram; (2) do comportamento atual e das condições que o afetam; e (3) das condições relacionadas ao comportamento futuro (Tourinho, 1995).

Nesse contexto de análise, quando alguém afirma que está com a auto-estima baixa, está falando da probabilidade de se comportar de uma dada maneira, e não informando uma condição corporal particular. Assim, para ajudar uma pessoa com baixa auto-estima deve-se investigar quais comportamentos acompanham esse sentir-se inferior diante de diversas situações e caracterizar o ambiente no qual esse comportamento se desenvolveu.

Primeiramente, deve-se identificar a história de privação de reforços, os déficits comportamentais, os comportamentos adequados na produção de reforços, sucessos e fracassos, as contingências do ambiente atual e o grau de assertividade. A partir desses dados, fazer uma análise funcional da vida desse indivíduo para poder esclarecê-lo sobre sua condição atual e como ela se estabeleceu a partir de sua história. Daí então, identificar outras classes de comportamentos que podem gerar melhores condições de reforço à medida que se reformula alguns conceitos sobre ele mesmo, os quais foram estabelecidos devido a esse período de malestar.

O treino discriminativo e em auto-controle podem auxiliar o cliente a conter verbalizações e comportamentos que antes produziam punições e, por meio do treino de habilidades, pode-se desenvolver um repertório mais amplo e eficaz na obtenção dos reforços desejados. Portanto, o indivíduo será capaz de se relacionar melhor com as pessoas a sua volta e conseqüentemente sentir-se melhor consigo mesmo e mais competente.

\section{Aspectos particulares da relação terapêutica no tratamento da auto-estima}

A relação terapeuta-cliente sempre foi um pré-requisito para se fazer psicoterapia, entretanto, nunca se falou tanto em relação terapêutica como nos últimos tempos. No tratamento da baixa auto-estima, alguns aspectos da relação terapêutica devem ser considerados com mais atenção, porque o cliente, quando se depara com a necessidade de reformulação de seu repertório comportamental, pode se sentir muito inadequado. 
Entre alguns aspectos importantes, o primeiro a ser salientado é a relação de confiança e aceitação. Trata-se da forma como se recebe o cliente e a postura de audiência diante dos relatos feitos por ele, ou seja, não desqualificar a história pessoal, não punir o relato verbal e demonstrar interesse pela pessoa do cliente.

Outro aspecto relaciona-se à resistência. O terapeuta está lidando com comportamentos fortemente instalados e que geram alguma segurança ao indivíduo. Fazer uma análise funcional da história do cliente, em conjunto com perguntas pertinentes para a obtenção de dados e promoção de esclarecimentos e reformulação de regras do indivíduo, realizar treinos de habilidades (instrumentar o cliente para lidar com o ambiente), entre outras coisas, aos poucos "quebram" a resistência à mudança. Mediante a apresentação de comportamentos adequados há o contato por parte do cliente com reforçadores naturais que são mais "interessantes".

Quanto ao reforço positivo na relação terapêutica, o terapeuta deve ter cuidado em buscar a história de sucessos do cliente, valorizando as ações bem sucedidas. O exagero no reforçar os comportamentos e valorizar o cliente pode acarretar em dificuldades na relação, pois a tendência é o cliente questionar o reforço e achar que é falso ("você está dizendo isso só porque é meu terapeuta"). A demonstração de afeto pelo terapeuta é outro pré-requisito para a terapia nesses casos. Se o cliente se sente rejeitado e vê o terapeuta como mais um que não o compreende, a terapia será ineficaz.

\section{Conclusão}

O tratamento da auto-estima sob a perspectiva analítico-comportamental tem por objetivo levar a pessoa a se perceber como igual às demais, reformulando conceitos sobre si própria e reorganizando seu repertório comportamental, levandoa a descobrir alternativas de comportamento que lhe permitam satisfazer as próprias necessidades. Dessa forma, ela não vai se relacionar com o outro fazendo exigências do que pode dar a si mesma e a relação vai ser mais fácil e gratificante para ambas.

Perante Deus, a natureza e o ambiente, todos os indivíduos são iguais. A diferença individual está na história (particular) complexa de contingências que forma o repertório comportamental de cada pessoa, mas que não tira a igualdade do ser. Em outras palavras: o fato das pessoas terem repertórios diferentes não caracteriza ninguém como superior ou inferior. Essa condição de igualdade pressupõe atitudes de respeito e consideração nas relações interpessoais, independente do aspecto físico, situação econômica ou social, já que cada um "acontece" como fenômeno biológico e não como resultado de qualquer escolha.

Do ponto de vista genético está comprovada a inexistência do ser humano melhor ou pior. A diferença está no que se aprende - e que muitas vezes dificulta 
a convivência, do ponto de vista social, moral ou religioso. Esse aprendizado nem sempre é facilmente modificado, carecendo de orientação de um especialista, de um conhecedor das leis que regem o comportamento.

Segundo Skinner (1991), “a auto-estima (o eu) em que acreditamos pode ser produto do fazer bem, e não sua causa. (...) Pessoas que não são bem sucedidas naquilo que fazem podem perder a fé em si mesmas, mas um terapeuta pode restaurala, fazendo com que se lembrem de sucessos anteriores, restabelecendo assim, pelo menos em parte, o estado corporal que sentiram nessas situações. O modo mais efetivo de restaurar a crença em si mesmo é, com certeza, restabelecer sucessos, talvez à custa de simplificar contingências de reforçamento" (p.48-49).

Muda-se a emoção mudando o que se faz. Ou, segundo Hayes (1987, citado em Brandão, 2000) "uma outra forma de mudar encobertos seria a estratégia chamada de separar o eu observador do eu como conteúdo. Se a pessoa se vê como eu observador de seus sentimentos e não como os seus próprios encobertos, ela poderá aceita-los melhor porque não precisa defender-se ou culpar-se por seus sentimentos. 'Eles são meus, mas não são eu'”, e ampliará sua possibilidade de compreender o que acontece e o que precisará fazer para mudar.

\section{Referências}

BALDWIN, J.D. \& BALDWIN, J.L. (1986). Behavior principles in everyday life. N. Jersey: Prentice Hall.

BAUM, W. (1999). Compreender o behaviorismo - ciência, comportamento e cultura. Porto Alegre (RS): Artes Médicas.

BRANDÃO, M.Z.S. (2000). Os sentimentos na interação terapeuta-cliente como recurso para a análise clínica. Em R. R. Kerbauy (Org.) Sobre comportamento e cognição: conceitos, pesquisa e aplicação, a ênfase no ensinar, na emoção e no questionamento clínico. São Paulo: ARBytes Editora.

FERREIRA, A.B.H. (2000). Dicionário Aurélio básico da língua portuguesa. Rio de Janeiro: Nova Fronteira.

SKINNER, B. F. (1953). Ciência e comportamento humano. São Paulo: Martins Fontes.

SKINNER, B. F. (1984). Contingências de reforço. (Os Pensadores) São Paulo: Abril Cultural.

SKINNER, B. F. (1991). Questões recentes na análise comportamental. Campinas, SP: Papirus.

TOURINHO, E. Z. Eventos privados em uma ciência do comportamento. Trabalho apresentado no IV Encontro Brasileiro de Psicoterapia e Medicina Comportamental. Campinas, SP, 1995. 